\title{
Effects of apelin-13 on myocardial ischemia reperfusion injury in streptozotocine induced diabetic rats
}

\author{
Gunes $\mathrm{I}^{1}$, Kartal $\mathrm{H}^{2}$, Dursun $\mathrm{AD}^{3}$, Sungu $\mathrm{N}^{4}$, Polat $\mathrm{Y}^{5}$, Erkent $\mathrm{FD}^{6}$, Arslan $\mathrm{M}^{6}$, Kucuk $\mathrm{A}^{7}$ \\ Department of Anaesthesiology and Reanimation, Erciyes University Medical Faculty, Kayseri, Turkey. \\ mustarslan@gmail.com
}

\begin{abstract}
AIM: We want to investigate the protective effects of apelin-13 on myocardial ischemia reperfusion (I/R) injury. MATERIAL AND METHODS: 30 Wistar Albino rat were divided into 5 groups $(n: 6)$, namely control group (C), diabetes group (D), diabetes+apelin-13 group (DA), diabetes+I/R group (DIR) and diabetes I/R+apelin-13 group (DIR-A). Rats were subjected to 30-min ischemia and 90-min reperfusion. Biochemical and histopathological parameters were measured.

RESULTS: Caspase-3 enzyme activity was significantly higher in the DIR group than in the C, DA, and DIRA groups. The intensity of caspase 3 enzyme activity was significantly higher in the I/R group than in all other groups. Inflammation and vascular dilatation were found significantly higher in the DIR group than in all other groups. Congestion was significantly higher in the DIR group than in the $C$ and D groups. TOS enzyme activity was significantly higher in the DIR group than in the C, DA and DIR-A groups. TAS enzyme activity was significantly lower in the DIR group than in the C and DIR-A groups.

CONCLUSION: We believe that the protective effects of apelin-13 in ischemia-reperfusion injury and its use indications can be demonstrated in detail as long as the findings we have reached in our study are supported by other studies (Tab. 2, Fig. 10, Ref. 43). Text in PDF www.elis.sk.

KEYWORDS: diabetes mellitus, apelin-13, TOS, TAS, caspase-3, ischemia reperfusion.
\end{abstract}

\section{Introduction}

In the past 20 or 30 years the prevalence of diabetes mellitus (DM) has rapidly increased throughout the world, and experts estimate that it is going to increase by $200 \%$ in the next several decades (1).

A $50 \%$ increase in early mortality following coronary artery bypass grafting has been described in diabetic patients (2). Margolis et al showed that the rate of unrecognized myocardial infarction was $39 \%$ in diabetic patients while in non-diabetic patients it was $22 \%$ (3). Cardiac surgery with cardiopulmonary bypass inevitably causes a systemic inflammatory response and ischemia-reperfusion (I/R) injury affecting multiple organs (1). Several drugs have been used to prevent I/R injury, including Vitamin $\mathrm{C}$, levosimendan, and dexmedetomidine $(1,4,5)$.

${ }^{1}$ Department of Anaesthesiology and Reanimation, Erciyes University Medical Faculty, Kayseri, Turkey, ${ }^{2}$ Department of Cardiovascular Surgery, Ardahan State Hospital, Ardahan, Turkey, ${ }^{3}$ Department of Physiology, Ankara University Medical Faculty, Ankara, Turkey, ${ }^{4}$ Department of Pathology, Yildirim Beyazit University Medical Faculty, Ankara, Turkey, ${ }^{5}$ Department of Cardiovascular Surgery, Mehmet Akif Ersoy Thoracic and Cardiovascular Surgery Training and Research Hospital, Istanbul, Turkey, ${ }^{6}$ Department of Anaesthesiology and Reamination, Gazi University Medical Faculty, Ankara, Turkey, and ${ }^{7}$ Department of Physiology, Dumlupinar University Medical Faculty, Kütahya, Turkey

Address for correspondence: M. Arslan, Dr, Gazi University, Medical Faculty, Anesthesiology and Reanimation Department, 06510 Ankara, Turkey.

Phone: +90.533 .4228577$
Apelin is a recently discovered peptide encoded by APLN gene in humans and it is an endogenous ligand of the human Gprotein-coupled apelin receptor (APJ); 6). The APLN gene encodes a 77-amino acid prepropeptide divided by shorter mature peptides such as apelin-13, apelin-17 and apelin-36 (7). The most studied apelins are apelin-13 and apelin-36 (8). There is increasing evidence suggesting that apelin regulates multiple physiological functions, including fluid homeostasis, food intake, cell proliferation, blood pressure regulation, angiogenesis, and glucose utilization ( 8 , 9). Therefore, it may be associated with diabetes, obesity, hypertension and / or cardiovascular diseases $(9,10)$. In spite of its increased clinical use the effects of apelin-13 on myocardial injury induced by left coronary artery (LAD) I/R have not yet been investigated.

This study was carried out to investigate the possible protective role of apelin-13, which is the most active form of apelin and has the highest biological activity against oxidative damage caused by myocardial $\mathrm{I} / \mathrm{R}$ in diabetic rats.

\section{Materials and methods}

\section{Animals and experimental protocol}

This study was conducted in the GUDAM Laboratory of Gazi University with the consent of Experimental Animals Ethics Committee of Gazi University. All of the procedures were performed according to the accepted standards of the Guide for the Care and Use of Laboratory Animals.

Thirty female Wistar Albino rats (180-220 g) were used. The rats were kept at $20-21^{\circ} \mathrm{C}$ in cycles of 12 hours of daylight and 12 
hours of darkness and had free access to food until two hours before the anesthetic procedure. The animals were randomly separated into five groups, each containing six rats. Control group (C), diabetes group (D), diabetes+apelin-13 (DA), diabetes+ischemia-reperfusion (DIR), and diabetes+ischemia-reperfusion+apelin-13 (DIR-A).

Diabetes was induced by a single injection of streptozotocin (Sigma Chemical, St. Louis, MO, USA), at a dose of $55 \mathrm{mg} / \mathrm{kg}$ (i.p.) body weight. Seventy-two hours after the injection, the blood glucose levels were measured. Rats were classified as diabetic if their fasting blood glucose (FBG) levels exceeded $250 \mathrm{mg} / \mathrm{dl}$, and only animals with FBGs of $>250 \mathrm{mg} / \mathrm{dl}$ were included in the diabetic groups (diabetes, diabetes+apelin-13, diabetes + ischemiareperfusion and diabetes+apelin-13-ischemia-reperfusion). The rats were kept alive for four weeks after streptozotocin injection to allow chronic diabetes to develop before exposing them to I/R (11). All the rats were weighed before the study. Rats underwent left thoracotomy and received apelin-13 (i.p.; apelin-13 trifluoroacetate salt, Sigma Aldrich), $10 \mu \mathrm{g} / \mathrm{kg}$, administrated via i.p. route 30 minutes before ligating the LAD (13). A small plastic snare was threaded through the ligature and placed in contact with the heart. The artery could then be occluded by applying tension to the ligature (30 minutes), and reperfusion was achieved by releasing the tension (90 minutes). However, after the above procedure, the coronary artery was not occluded or reperfused in the control, diabetic and diabetic+apelin-13 rats.

Rats were anesthetized with $100 \mathrm{mg} / \mathrm{kg}$ (i.p.) ketamine. The trachea was cannulated for artificial respiration. The chest was shaved and each animal was fixed in a supine position on the operating table. The chest was opened by left thoracotomy followed by sectioning the fourth and fifth ribs about $2 \mathrm{~mm}$ to the left of the sternum. Positive-pressure artificial respiration was started immediately with room air, using a volume of $1.5 \mathrm{ml} / 100 \mathrm{~g}$ body weight at a rate of $60 \mathrm{strokes} / \mathrm{min}$. Sodium heparin $(500 \mathrm{IU} / \mathrm{kg})$ was administered through the peripheral vein in the tail.

After the pericardium was incised, the heart was exteriorized with gentle pressure on the right side of the rib cage. An 8/0 silk suture attached to a $10-\mathrm{mm}$ micropoint reverse-cutting needle was quickly placed under the left main coronary artery. The heart was then carefully replaced in the chest and the animal was allowed to recover for 20 minutes. All the rats were given ketamine $100 \mathrm{mg} /$ $\mathrm{kg}$ (i.p.) and intracardiac blood samples were taken.

\section{Homogenization of tissues}

The heart tissue was collected into a sterile eppendorf tube and kept at $-80{ }^{\circ} \mathrm{C}$ until being analyzed for total antioxidant/oxidant status. Without being allowed to dissolve, the tissues were quickly weighed on a precision scale and separated as $80-100 \mathrm{mg}$ using a no. 22 lancet (PLUSMED®). Tissue fragments were smashed in the presence of liquid nitrogen in a porcelain bowl. The powdered tissue was transferred to the homogenization tube and for each gram of tissue, $140 \mathrm{mM} \mathrm{KCI}$ solution was added such that the dilution was $1 / 10$. In order not to increase the temperature, a homogenization tube was held in a snow-filled glass beaker and after homogenization with a homogenizer (Glas_Col K5424®) at a speed of 50 revolutions per minute (rpm) for two minutes, the homogeni- zation process was completed. The homogenate was transferred to an eppendorf tube. Eppendorf tubes were coated with parafilm and then centrifuged (Hettich Micro 200R $®$ ) for 10 minutes at $3000 \mathrm{rpm}$. After centrifugation, the supernatant was taken into another eppendorf tube and TOS and TAS levels were measured.

\section{Total antioxidant status (TAS)}

TAS was measured by a TAS test kit (RelAssay Diagnostic $\AA$, Turkey). For TAS measurement, as described in kit's procedure, $500 \mu \mathrm{L}$ of reagent 1 (measurement buffer) and $30 \mu \mathrm{L}$ of sample were mixed and absorbance was measured at $660 \mathrm{~nm}$ by a spectrophotometer (NanoDrop $\left.{ }^{\circledR} \mathrm{ND}-1000\right)\left(\mathrm{A}_{1}\right)$. A volume of $75 \mu \mathrm{L}$ of reagent 2 (colored 2,2-azino-bis-3-ethylbenzothiazoline-6-sulfonic acid; ABTS) was added to the mixture in the Eppendorf tube. The tube was coated with paraffin and incubated for 5 minutes in a hot water bath at $37^{\circ} \mathrm{C}$ (Lightning Laborteknik ${ }^{\circledR}$ ). After incubation, absorbance measurement was performed at $660 \mathrm{~nm}\left(\mathrm{~A}_{2}\right)$. For standard measurement, the Trolox Eq solution at a concentration of $1 \mathrm{mmol} / \mathrm{L}$ was used instead of the sample. The first and second measurements were made for three times and their averages were measured. The absorbance change ( $\triangle \mathrm{Abs}$ ) was calculated by subtracting the first absorbance value (A1) from the second absorbance value (A2). TAS levels were calculated using the formula given in the kit and expressed as mmol Trolox Eq / L.

$\mathrm{TAS}=[(\Delta \mathrm{AbsH} 2 \mathrm{O}-\Delta \mathrm{Abs}$ Sample $) /(\Delta \mathrm{Abs} H 2 \mathrm{O}-\Delta \mathrm{Abs}$ Standard)]

\section{Total oxidative status (TOS)}

TOS was measured by a TOS test kit (RelAssay Diagnostic $\AA$, Turkey). For TOS measurement, as described in kit's procedure, $500 \mu \mathrm{L}$ of reagent 1 (measurement buffer) and $75 \mu \mathrm{L}$ of sample were mixed and absorbance was measured at $530 \mathrm{~nm}$ by a spectrophotometer (NanoDrop ${ }^{\circledR} \mathrm{ND}-1000 ; \mathrm{A}_{1}$ ). A volume of $25 \mathrm{~mL}$ of reagent 2 (Pro-chromogenic solution) was added to the mixture. The tube was coated with paraffin and incubated for 5 minutes in a hot water bath at $37{ }^{\circ} \mathrm{C}$ (Lightning Laborteknik $\left.{ }^{\circledR}\right)$. After incubation, absorbance measurement was performed at $530 \mathrm{~nm}\left(\mathrm{~A}_{2}\right)$. A standard solution containing $10 \mu \mathrm{mol} / \mathrm{L}$ hydrogen peroxide $\left(\mathrm{H}_{2} \mathrm{O}_{2}\right)$ equivalent / liter given in the kit was used for standard measurement. The first and second measurements were made for three times and their averages were measured. The absorbance change $(\triangle \mathrm{Abs})$ was calculated by subtracting the first absorbance value (A1) from the second absorbance value (A2). TOS levels were calculated using the formula given in the kit and expressed as mmol $\mathrm{H}_{2} \mathrm{O}_{2} \mathrm{Eq} / \mathrm{L}$.

TOS $=[(\Delta$ Abs sample $) /(\Delta$ Abs standard $)] \times$ Standard Concentration $(10 \mu \mathrm{mol} / \mathrm{L})$.

\section{Histochemical and immunohistochemical evaluation}

At the end of each experiment, one of the myocardial tissue in each rat was fixed in $10 \%$ buffered formalin for $48 \mathrm{~h}$, dehydrated in a graded ethanol series, cleaned in xylene, and embedded in paraffin wax, and sections of 5- $\mu \mathrm{m}$ thickness were cut using a sliding microtome (Leica Microsystems, Germany). Tissue sections were stained with hematoxylin-eosin (H\&E). 
Tab. 1. Histological parameters (mean $\pm \mathrm{SE})$.

\begin{tabular}{|c|c|c|c|c|c|c|}
\hline & $\begin{array}{c}\text { Group C } \\
(\mathrm{n}=6)\end{array}$ & $\begin{array}{c}\text { Group D } \\
(\mathrm{n}=6)\end{array}$ & $\begin{array}{c}\text { Group DA } \\
(\mathrm{n}=6)\end{array}$ & $\begin{array}{c}\text { Group DIR } \\
(\mathrm{n}=6)\end{array}$ & $\begin{array}{c}\text { Group DIR-A } \\
(\mathrm{n}=6)\end{array}$ & $\mathrm{P} * *$ \\
\hline Caspase -3 (1: less than 50\%, 2: more than 50\%) & $1.00 \pm 0.00^{*}$ & $1.20 \pm 0.20$ & $1.00 \pm 0.00^{*}$ & $1.60 \pm 0.25$ & $1.00 \pm 0.00^{*}$ & 0.028 \\
\hline Caspase-3 (1: poor staining, 2: strong staining) & $1.00 \pm .0 .00^{*}$ & $1.40 \pm 0.25^{*}$ & $1.20 \pm 0.20^{*}$ & $2.00 \pm 0.00$ & $1.20 \pm 0.20^{*}$ & 0.005 \\
\hline Edema & $0.00 \pm .0 .00$ & $0.00 \pm 0.00$ & $0.00 \pm 0.00$ & $0.00 \pm 0.00$ & $0.00 \pm 0.00$ & - \\
\hline Inflammation & $0.00 \pm .0 .00^{*}$ & $0.20 \pm 0.20^{*}$ & $0.00 \pm 0.00^{*}$ & $0.80 \pm 0.20$ & $0.00 \pm 0.00 *$ & 0.001 \\
\hline Fibrosis & $0.00 \pm .0 .00$ & $0.00 \pm 0.00$ & $0.00 \pm 0.00$ & $0.00 \pm 0.00$ & $0.00 \pm 0.00$ & - \\
\hline Vascular dilatation & $0.00 \pm .0 .00^{*}$ & $0.60 \pm 0.40^{*}$ & $0.00 \pm 0.00^{*}$ & $1.80 \pm 0.20$ & $0.40 \pm 0.40 *$ & 0.001 \\
\hline Congestion & $1.00 \pm .0 .00^{*}$ & $1.40 \pm 0.25^{*}$ & $1.60 \pm 0.25$ & $2.00 \pm 0.00$ & $1.60 \pm 0.20$ & 0.021 \\
\hline Steatosis & $0.00 \pm .0 .00$ & $0.00 \pm 0.00$ & $0.00 \pm 0.00$ & $0.00 \pm 0.00$ & $0.00 \pm 0.00$ & - \\
\hline
\end{tabular}

$\mathrm{p}^{* *}$ : significance level with Kruskal-Wallis test $\mathrm{p}<0.05,{ }^{*} \mathrm{p}<0.05$ : compared with Group DIR

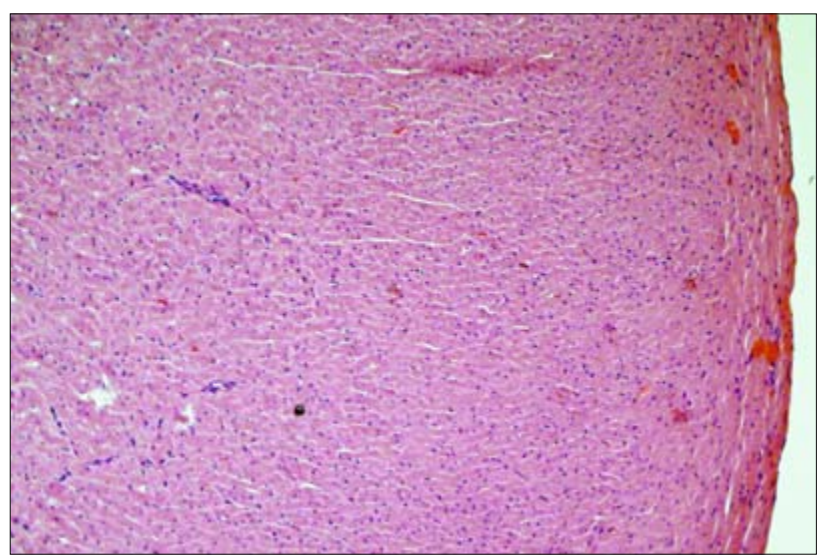

Fig. 1. Control Group. Conjugate vein structures are observed in the heart muscle. Edema, inflammation, fibrosis, vascular dilatation and fatigue are not observed in heart-muscle cells (H\&Ex100).

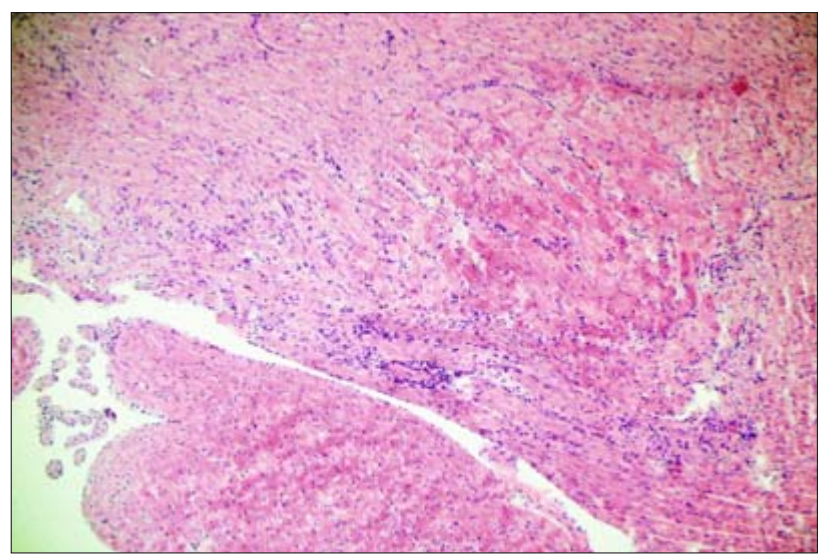

Fig. 2. Diabetes group. Severe inflammation of the interstitial area is observed in the heart muscle (H\&Ex100).

All the sections were performed by the same pathologist who was blinded to the study. The scoring system was used for histopathological evaluation of the myocardial tissues. Interstitial edema, congestion, vascular dilatation, inflammation, fibrosis and steatosis were scored from 0 to +2 for each parameter and the total of these parameter scores was used for determining the final tissue damage. The scores of each parameter represented the severity of the pathological finding as follows: 0 : no pathologic lesions, 1 : low finding, 2: high pathological finding in myocardial tissue section.

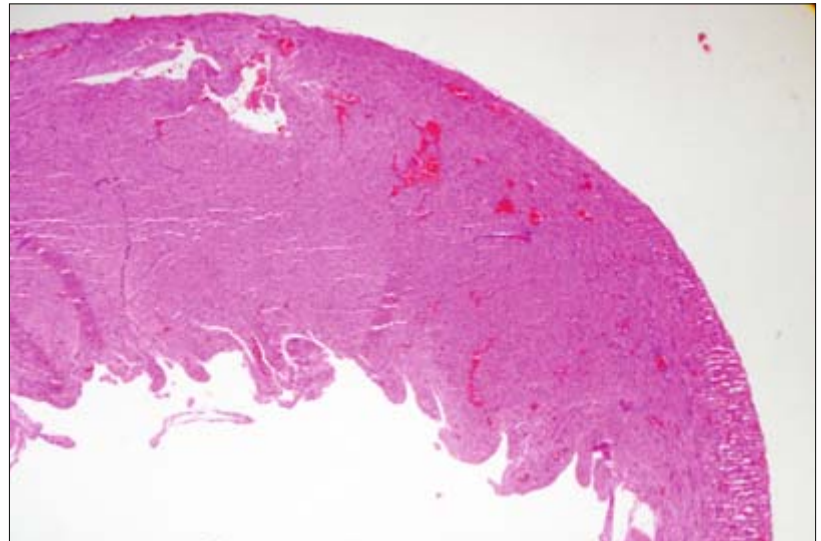

Fig. 3. Diabetes+apelin-13 group. Vessels containing mild congestion are observed in the heart muscle (H\&Ex40).

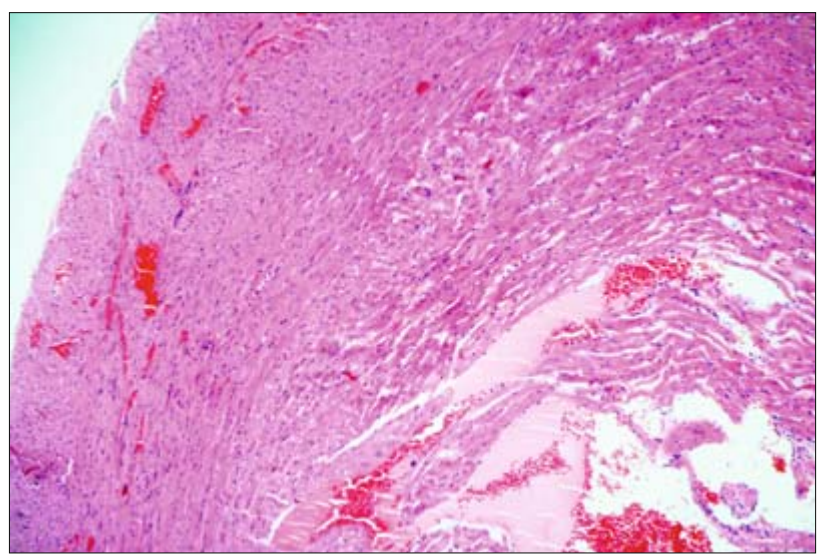

Fig. 4. Diabetes+ischemia-reperfusion group. Scoring 2 congestion and dilatation vein structures are observed in the heart muscle (H\&Ex100).

Immunohistochemical evaluation

For immunohistochemical studies, complete surface sections of 3-4 $\mu \mathrm{L}$ of poly-L-lysine-coated slides were prepared from formalin-fixed paraffin-embedded blocks of biopsy specimens in all of the events. The sections were left overnight at 45 degrees. Standard antigen retrieval methods, namely deparaffinization, blocking, primer antibody (Caspase-3: Citrate $30 \mathrm{~min}$ ), postprimer, and polymer, DAP were used in Bond-maximal immunohistochemistry (Leica) device for Caspase-3 (p11, C-6, 1/400, 


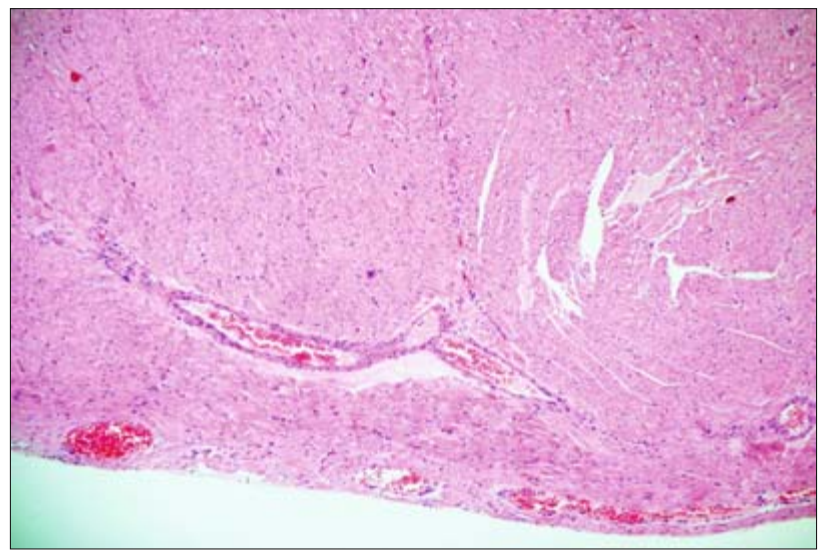

Fig. 5. Diabetes+ischemia-reperfusion+apelin-13 group. Vessels containing mild congestion are observed in the heart muscle (H\&Ex100).

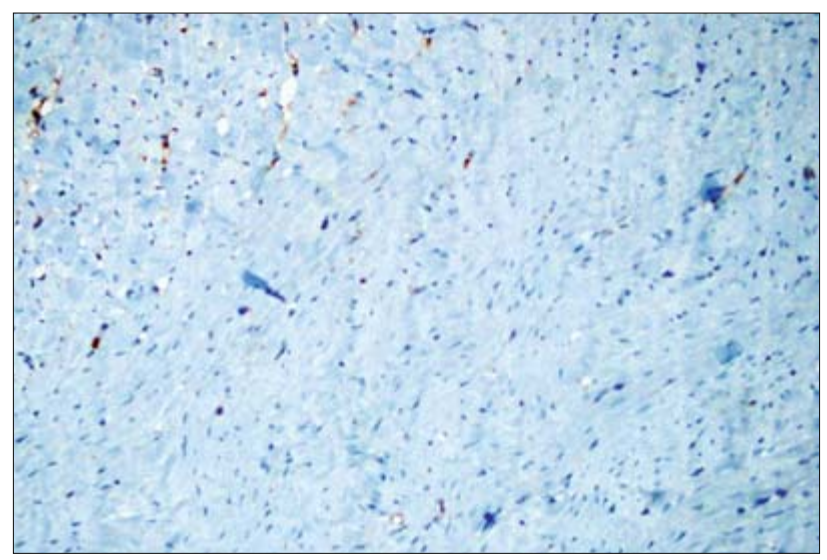

Fig. 6. Control group. Less than $50 \%$ of vascular endothelia are weakly stained with caspase-3 (caspase- $3 \times 200$ ).

mouse monoclonal antibody) antibodies immunohistochemically. Hematoxylin II and blue reagent were applied in the background dye for 6 and $4 \mathrm{~min}$, respectively.

Immunohistochemical staining preparations were washed in water and alcohol and after being clarified with xylene they were covered with balsam. The intensity and severity of immunohistological staining in vascular endothelium were evaluated with Caspase- 3 . The intensity was scored as follows: 0 : no staining, 1 : less than $50 \%, 2$ : more than $50 \%$. The severity was scored as follows: 0 : no staining, 1: poor staining, 2: strong staining.

\section{Statistical analysis}

All the data were processed by variance analysis in the Statistical Package for the Social Sciences (SPSS, Chicago, IL, USA)

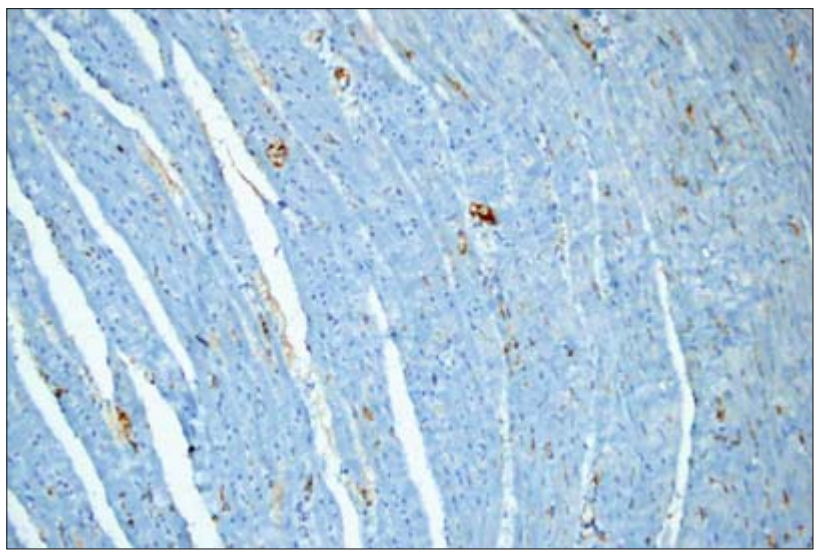

Fig. 7. Diabetes group. In the presence of severe inflammation and mild congestion, caspase-3 has weaker staining in more than $50 \%$ of vascular endothelium (caspase-3 x200).

20.0 program for Windows statistical software. Kruskal-Wallis test was used to assess the results. Bonferroni-adjusted Mann-Whitney U test was used after significant Kruskal-Wallis to determine which group differs from the other. The data were expressed as mean \pm standard error (Mean \pm SE). Value of $\mathrm{p}<0.05$ was considered statistically significant.

\section{Results}

Caspase-3 enzyme activity was significantly higher in the DIR group than in the C, DA, and DIR-A groups $(\mathrm{p}=0.007$, all). The intensity of caspase- 3 enzyme activity was significantly higher in the DIR group than in all other groups $(\mathrm{p}<0.0001, \mathrm{p}=0.020, \mathrm{p}$ $=0.003, \mathrm{p}=0.003$, respectively) (Tab. 1, Figs 1-5).

Inflammation and vascular dilatation were found significantly higher in the DIR group than in the other groups. Congestion was significantly higher in the DIR group than in the $\mathrm{C}$ and $\mathrm{D}$ groups ( $p=0.001, p=0.037$, respectively) (Tab. 1, Figs 6-10).

TOS enzyme activity was significantly higher in the DIR group than in the C, DA, and DIR-A groups $(\mathrm{p}=0.001, \mathrm{p}=0.013, \mathrm{p}=$ 0.003 , respectively). TAS enzyme activity was significantly lower in the DIR group than in the C and DIR-A groups ( $\mathrm{p}=0.009, \mathrm{p}=$ 0.036 , respectively) (Tab. 2).

\section{Discussion}

Myocardial ischemia and the following reperfusion is often a fatal consequence of increased oxygen requirement and/or diminished oxygen supply to the myocardium. Thirty minutes after

Tab. 2. Oxidative Status Parameters (mean $\pm \mathrm{SE}$ ).

\begin{tabular}{lccccc}
\hline & $\begin{array}{c}\text { Group C } \\
(\mathrm{n}=6)\end{array}$ & $\begin{array}{c}\text { Group D } \\
(\mathrm{n}=6)\end{array}$ & $\begin{array}{c}\text { Group DA } \\
(\mathrm{n}=6)\end{array}$ & $\begin{array}{c}\text { Group DIR } \\
(\mathrm{n}=6)\end{array}$ & $\begin{array}{c}\text { Group DIR-A } \\
(\mathrm{n}=6)\end{array}$ \\
\hline TOS $\left(\mathrm{mmol} \mathrm{H} \mathrm{O}_{2} \mathrm{Eq} / \mathrm{l}\right)$ & $6.95 \pm 1.59 *$ & $12.30 \pm 3.68$ & $9.94 \pm 5.22 *$ & $16.57 \pm 3.04$ & $8.45 \pm 4.64 *$ \\
\hline TAS $(\mathrm{mmol}$ Trolox Eq/1) & $1.14 \pm 0.78^{*}$ & $0.63 \pm 0.09$ & $0.63 \pm 0.12$ & $0.36 \pm 0.09$ & 0.019 \\
\hline
\end{tabular}

$\mathrm{p}^{* *}$ : significance level with Kruskal-Wallis test $\mathrm{p}<0.05,{ }^{*} \mathrm{p}<0.05$ : compared with Group DIR 


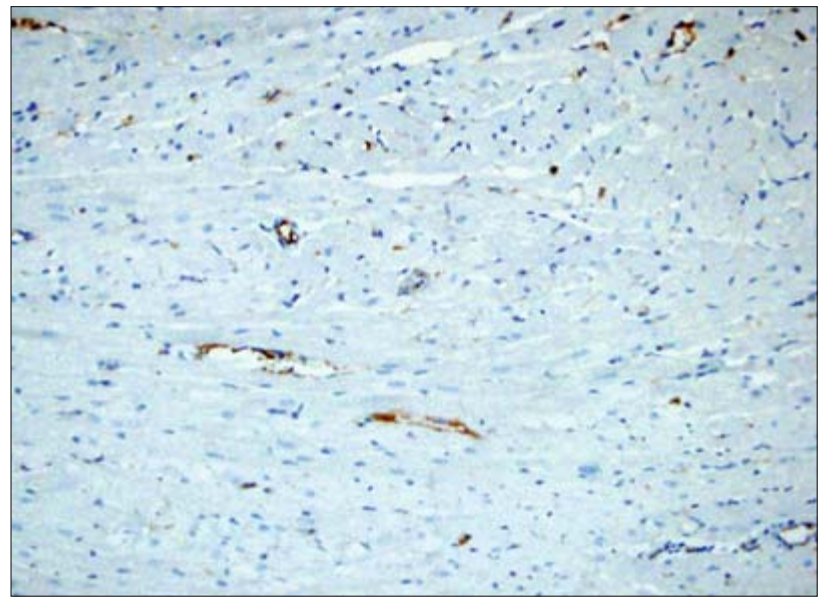

Fig. 8. Diabetes+apelin-13 group. There is strong staining with less than $50 \%$ of vascular endothelia with caspase-3 (caspase-3 x200).

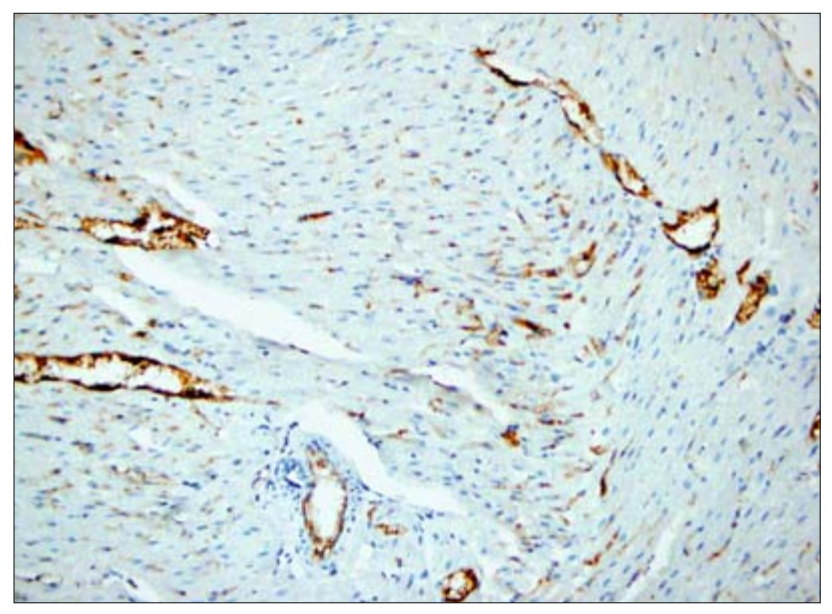

Fig. 9. Diabetes+ischemia-reperfusion group. There is more than $50 \%$ staining of vascular endothelia with caspase-3.

coronary ligation, the signs of cellular injury start, and if duration of coronary occlusion lengthens out, the signs of irreversible myocardial injury occur, caused by contraction band necrosis and myocytolysis. After a period of ischemia (60 min) and reperfusion (60 min), edematous and nuclear changes such as chromatin clumping and swelling, apoptosis induced by increased $\mathrm{Bcl}-2$, and Fas ligand are observed. Also, glycogen depletion, mitochondrial swelling, and dilatation of sarcoplasmic reticulum are observed 60 min after occlusion (12).

Yang et al (13) reported in their study that apelin could activate multiple protective mechanisms to prevent injury to the heart, brain, liver and kidney. Apelin/APJ system may be a promising therapeutic target for ischemic and other related diseases. Studies carried out report that apelin decreases the oxidative stress in the cardiomyocytes and veins of smooth muscle cells $(14,15)$.

Studies in mice and rats show that apelin has an analgesic role in acute pain models. (16-18). Xu et al (16) presents evidence that apelin-13 plays a significant role in the modulation of pain response at the supraspinal level in mice.

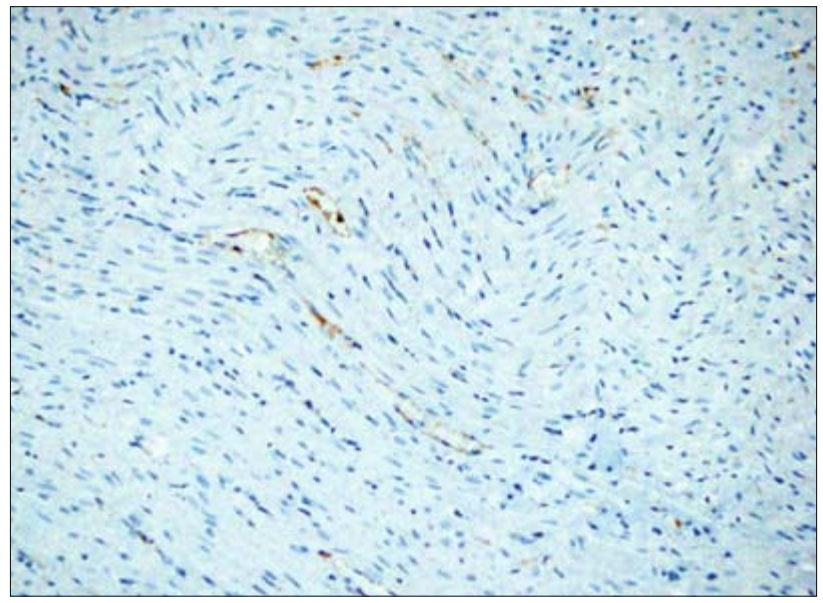

Fig. 10. Diabetes-ischemia-reperfusion-apelin-13 group. Less than $50 \%$ of vascular endothelia are weakly stained with caspase-3.

Another study has also similar results, indicating that intracerebroventricular and intrathecal (but not intraperitoneal) injection of apelin-13 induced an antinociceptive effect in the acetic acid-induced visceral pain in a mouse model. The APJ receptor and $\mu$-opioid receptor were involved in the antinociception of i.c.v. apelin-13 and apelin-13 $(0.3 \mu \mathrm{g})$ significantly potentiated the analgesic potencies of morphine (17).

Turtay et al (18) aimed herein to compare the possible analgesic effects of apelin-13 and morphine, and to reveal the mechanistic pathways underlying the analgesic effects of apelin-13 co-administered with serotonin and nitric oxide, in a rat model indexed by analgesic response times during hot-plate and tail-flick tests. Their results demonstrate that apelin-13 exerts an analgesic effect; co-administration of apelin-13 and ondansetron inhibits antinociception, an effect apparently mediated by five hydroxytryptamine-three (5-HT3) receptors. These results should facilitate the analysis of the role of apelin-13 in acute pain and may open novel pharmacological interventions.

Unpaired electrons, free radicals, are highly reactive and readily take part in chemical reactions with virtually all cell components (lipids, proteins, complex carbohydrates and nucleic acids) in the body. These reactions occur through a chain of oxidative reactions to cause tissue injury. For most biological structures (like lipids, proteins, and nucleic acids), free radical damage is closely associated with oxidative damage, causing direct cellular injury by inducing lipid and protein peroxidation and damaging nucleic acids (19). I/R results in the generation of toxic reactive oxygen species (ROS) in the organs. Ischemia reduces the activity of cellular defense enzymes against ROS, and reperfusion or the introduction of oxygen further disturbs the delicate balance of oxidants/antioxidants (20) while intracellular calcium overload, adenosine triphosphate depletion, myocardial apoptosis, and endothelial dysfunction are all observed as a result of this $(21,22)$. Also, oxidative products such as ROS, reactive nitrogen species, hydrochloric acid, MDA, and lipid peroxides constitute TOS (23). 
Serum concentrations of different oxidative components can be measured in the laboratory separately, but the measurement of these molecules is labor-intensive, requires much time, and complicated techniques, and is costly. TAS and TOS reflect the redox balance between oxidation and antioxidation. TAS measurement is an indicator of the activity of all antioxidants while TOS is an indicator of $\operatorname{ROS}(24,25)$.

Oxidative stress is an oxidant-antioxidant imbalance status, due to oxidants which exceed the antioxidant capacity. OSI is the ratio of TOS to TAS and is an indicator of OS degree $(24,25)$. It may offer a more accurate comment for the evaluation of the change in oxidant-antioxidant balance. Mentese et al studies found a significant increase in OSI values at Rp $30 \mathrm{~min}$. This finding suggested the development of oxidative imbalance or increase in the degree of OS in ONCABG patients (26).

In this study, TAS, as a marker of total antioxidant protection against the attack of free radicals in the organism and TOS, as a marker of total value of OS were used. Studies have shown that TAS measurement provides more valuable information than individual measurements of antioxidants $(27,28)$.

When we compared myocardial tissue in terms of TOS enzyme activity in our study, there was a significant difference between the groups. TOS enzyme activity was significantly higher in DIR group when compared with that of C, D and DIR-A groups. Oxidative stress, which is the primary actor of I/R injury, was found to be lower in the apelin-13-treated groups in the TOS measurement.

When comparing myocardial tissue in terms of TAS enzyme activity in our study, there was a significant difference between the groups. TAS enzyme activity was found to be significantly higher in DIR group than in C, D and DIR-A groups, which is parallel to the fact that antioxidant systems are impaired by $\mathrm{I} / \mathrm{R}$ damage, while the low activity of TAS enzyme in the groups given apelin-13 indicates that the antioxidant systems are protected, in other words active. Kim et al (29) found that administration of $2.5 \mathrm{mg}$ vitamin $\mathrm{C}$ during 5 days increased the TAS levels, and after the administration of $2.5 \mathrm{mg}$ vitamin $\mathrm{C}$ for 5 days, TAS was found to be decreased. They thought that this decrease in TAS was related to a decrease in antioxidant stress. To the best of our knowledge, in this study, for the first time, it has been reported that I/R of the diabetic rat heart results in significant negative changes that can be observed in myocardial tissue and that the apelin signaling mediated important events in cardiovascular homeostasis. At the same time, apelin-13 has been shown to have a positive effect on myocardial contractility by promoting a potent positive inotropic effect and when administered at the beginning of heart ischemia it can provide varying degrees of protection against negative effects of variations in myocardial injury.

Recent studies suggested that apelin signaling mediated important events in cardiovascular homeostasis and has been shown to have a positive effect on myocardial contractility by promoting a potent positive inotropic effect $(30,31)$. Apelin is a vasodilatator both in in-vivo (32) and ex-vivo models employing human arteries and veins (33). Accordingly, intravenous apelin administration in rodents reduces mean arterial pressure (34), systemic venous tone (35), and cardiac preload and afterload (30).
Rastaldo et al have found that apelin-13 could limit infarct size and improve cardiac post-ischemic mechanical recovery only if given after ischemia (36). Furthermore, Tao et al (37) reported that apelin-13 protects the heart against I/R injury through inhibition of endoplasmic reticulum-dependent apoptotic pathways.

Some reports have shown that ischemic pre- and post-conditioning could decrease cell apoptosis and myocardial injury, which could activate the PI3K/Akt and ERK1/2 signal, phosphorylate eNOS, p70S6K, GSK-3 $\beta$, GLUT4 and anti-apoptosis proteins such as Bcl-2, Bad, Bax, Caspase, as a result of which the delivery of Cyt-C is inhibited and cell apoptosis is blocked (38-43).

Apelin signaling may have an important role in the physiopathology of diseases such as hypertension, heart failure, cardiovascular disease, type- 2 diabetes, and obesity, although their effects and functions are still unclear. The physiological effects of apelin on diabetes are not fully known.

We can conclude that both types of apelin effectively decrease heart tissue injury following LAD clamping-induced I/R injury in the diabetic rat. Additionally, apelin-13 administered before induction of ischemia was observed to have protective effects on these alterations in myocardial I/R injury. Other aspects of these findings, including clinical significance and practical applications, merit further experimental and clinical investigation.

\section{References}

1. Comu FM, Oztürk L, Alkan M, Pampal K, Arslan M, Işik B et al. Investigation of effects of the propofol and vitamin $\mathrm{C}$ administration on erythrocyte deformability in rats with streptozotocin-induced diabetes mellitus. Bratisl Med J 2014; 115 (7): 400-404.

2. Giquel J, Rodriguez-Blanco YF, Matadial C, Candiotti K. Diabetes mellitus in anaesthesia. Br J Diabetes Vasc Dis 2012; 12: 60-64.

3. Margolis JR, Kannel WS, Feinleib M, Dawber TR, McNamara PM. Clinical features of unrecognized myocardial infarction silent and symptomatic. Eighteen year follow-up: Framingham study. Am J Cardiol 1973; 32: 1-7.

4. Arslan M, Poyraz F, Kiraz HA, Alkan M, Kip G, Erdem Ö et al. The effect of dexmedetomidine on myocardial ischaemia reperfusion injury in streptozotocin induced diabetic rats. Anaesth Pain \& Intensive Care 2015; 19: 444-451.

5. Kiraz HA, Poyraz F, Kip G, Erdem Ö, Alkan M, Arslan M et al. The effect of levosimendan on myocardial ischaemia reperfusion injury in streptozotocin induced diabetic rats. Libyan J Med 2015; 7: 10.

6. Tatemoto K, Hosoya M, Habata Y, Fujii R, Kakegawa T, Zou MX et al. Isolation and characterization of a novel endogenous peptide ligand for the human APJ receptor. Biochem Biophys Res Commun 1998; 251: 471-476.

7. Japp AG, Newby DE. The apelin-APJ system in heart failure: Pathophysiologic relevance and therapeutic potential. Biochem Pharmacol 2008; 75: $1882-1892$.

8. Salcedo A, Garijo J, Monge L, Fern'andez N, Luis Garc'ia-Villal'on A, S'anchez Turri'on $\mathbf{V}$ et al. Apelin effects in human splanchnic arteries. Role of nitric oxide and prostanoids. Regul Pept 2007; 144: 50-55.

9. Sorli SC, Van den Berghe L, Masri B, Knibiehler B, Audigier Y. Therapeutic potential of interfering with apelin signalling. Drug Discov Today 2006; 11: 1100-1106. 
10. Falcao-Pires I, Ladeiras-Lopes R, Leite-Moreira AF. The apelinergic system: A promising therapeutic target. Expert Opin Ther Targets 2010; 14: 633-645

11. Türeci E, Iş M, Uzüm G, Akyüz F, Ulu MO, Döşoğlu M et al. Alterations in blood-brain barrier after traumatic brain injury in streptozotocininduced diabetic rats. J Nervous Sys Surgery 2009; 2(2): 79-86.

12. Asano G, Takashi E, Ishiwata T, Onda M, Yokoyama M, Naito Z et al. Pathogenesis and protection of ischemia and reperfusion injury in myocardium. Nippon Med Sch 2003; 70: 384-392.

13. Yang Y, Lv S-Y, Lyu S-K, Wu D, Chen Q. The protective effect of apelin on ischemia/reperfusion injury. Peptides 2015; 63: 43-46.

14. Foussal C, Lairez O, Calise D, Pathak A, Guilbeau-Frugier C, Valet $\mathbf{P}$ et al. Activation of catalase by apelin prevents oxidative stress-linked cardiac hypertrophy. FEBS Lett 2010; 584 (11): 2363-2370.

15. Chun HJ, Ali ZA, Kojima Y, Kundu RK, Sheikh AY, Agrawal R et al. Apelin signaling antagonizes Ang II effects in mouse models of atherosclerosis. J Clin Invest 2008; 118 (10): 3343-3354.

16. Xu N, Wang H, Fan L, Chen Q. Supraspinal administration of apelin-13 induces antinociception via the opioid receptor in mice. Peptides 2009; 30: 1153-1157.

17. Lv SY, Qin YJ, Wang NB, Yang YJ, ChenQ. Supraspinal antinociceptive effect of apelin-13 in a mouse visceral pain model. Peptides 2012; 37 (1): 165-170.

18. Turtay MG, Karabas M, Parlakpinar H, Colak C, Sagir M. The analgesic effect of apelin-13 and its mechanism of action within the nitric oxide and serotonin pathways. Hippokratia 2015; 19 (4): 319-323.

19. Halliwell B, Gutteridge JMC. Free Radicals in Biology and Medicine. 3rd ed. New York: Oxford University Press 1999. pp. 246-350.

20. McCord JM. Free radicals and myocardial ischemia: overview and outlook. Free Radic Biol Med 1988; 4: 9-14.

21. Mozaffari MS, Liu JY, Abebe W, Baban B. Mechanisms of load dependency of myocardial ischemia reperfusion injury. Am J Cardiovasc Dis 2013; 3: 180-196.

22. Turer AT, Hill JA. Pathogenesis of myocardial ischemia-reperfusion injury and rationale for therapy. Am J Cardiol 2010; 106: 360-368.

23. Ansari RA, Aswal BS, Chander R, Dhawan BN, Garg NK, Kapoor NK et al. Hepatoprotective activity of kutkin — the iridoid glycoside mixture of Picrorhiza kurroa. Indian J Med Res 1988; 87: 401-404.

24. Rabus M, Demirbağ R, Sezen Y, Konukoğlu O, Yildiz A, Erel O et al. Plasma and tissue oxidative stress index in patients with rheumatic and degenerative heart valve disease. Turk Kardiyol Dern Ars 2008; 36 (8): 536-540.

25. Erel O. A new automated colorimetric method for measuring total oxidant status. Clin Biochem 2005; 38 (12): 1103-1111.

26. Mentese U, Dogan OV, Turan I, Usta S, Dogan E, Mentese SO et al. Oxidant-antioxidant balance during on-pump coronary artery bypass grafting. Sci World J 2014; 263058.

27. Ghiselli A, Serafini M, Natella F, Scaccini C. Total antioxidant capacity as a tool to assess redox status: critical view and experimental data. Free Radic Biol Med 2000; 29 (11): 1106-1114.

28. Erel O. A novel automated direct measurement method for total antioxidant capacity using a new generation, more stable ABTS radical cation. Clin Biochem 2004; 37 (4): 277-285.
29. Kim JH, Kim YC, Nahm FS, Lee PB. The therapeutic effect of vitamin $\mathrm{C}$ in an animal model of complex regional pain syndrome produced by prolonged hindpaw ischemia-reperfusion in rats. Int J Med Sci 2017; 14 (1): 97-101.

30. Ashley EA, Powers J, Chen M, Kundu R, Finsterbach T, Caffarelli A et al. The endogenous peptide apelin potently improves cardiac contractility and reduces cardiac loading in vivo. Cardiovasc Res 2005; 65: 73-82.

31. Berry MF, Pirolli TJ, Jayasankar V, Burdick J, Morine KJ, Gardner TJ et al. Apelin has in vivo inotropic effects on normal and failing hearts. Circulation 2004; 110: II187-93.

32. Japp AG, Cruden NL, Amer DA, Li VK, Goudie EB, Johnston NR et al. Vascular effects of apelin in vivo in man. J Am Coll Cardiol 2008; 52: 908-913.

33. Maguire JJ, Kleinz MJ, Pitkin SL, Davenport AP. [Pyr1]apelin-13 identified as the predominant apelin isoform in the human heart: Vasoactive mechanisms and inotropic action in disease. Hypertension 2009; 54 : 598-604.

34. Ishida J, Hashimoto T, Hashimoto Y, Nishiwaki S, Iguchi T, Harada $\mathrm{S}$ et al. Regulatory roles for APJ, a seven-transmembrane receptor related to angiotensin-type 1 receptor in blood pressure in vivo. J Biol Chem 2004; 279: 26274-26279.

35. Cheng X, Cheng XS, Pang CC. Venous dilator effect of apelin, an endogenous peptide ligand for the orphan APJ receptor, in conscious rats. Eur J Pharmacol 2003; 470: 171-175.

36. Rastaldo R, Cappello S, Folino A, Berta GN, Sprio AE, Losano G et al. Apelin-13 limits infarct size and improves cardiac postischemic mechanical recovery only if given after ischemia. Am J Physiol Heart Circ Physiol 2011; 300: H2308-2315.

37. Tao J, Zhu W, Li Y, Xin P, Li J, Liu M et al. Apelin-13 protects the heart against ischemia-reperfusion injury through inhibition of ERdependent apoptotic pathways in a time-dependent fashion Am J Physiol Heart Circ Physiol 2011; Oct 301(4): H1471-1486.

38. Raphael J, Abedat S, Rivo J, Meir K, Beeri R, Pugatsch T et al. Volatile anesthetic preconditioning attenuates myocardial apoptosis in rabbits after regional ischemia and reperfusion via Akt signaling and modulation of Bcl-2 family proteins. J Pharmacol Exp Ther 2006; 318: 186-194.

39. Fujio Y, Nguyen T, Wencker D, Kitsis RN, Walsh K. Akt promotes survival of cardiomyocytes in vitro and protects against ischemia-reperfusion injury in mouse heart. Circulation 2000; 101: 660-667.

40. Li DY, Tao L, Liu H, Christopher TA, Lopez BL, Ma XL. Role of ERK1/2 in the anti-apoptotic and cardioprotective effects of nitric oxide after myocardial ischemia and reperfusion. Apoptosis 2006; 11: 923-930.

41. Hausenloy DJ, Tsang A, Mocanu MM, Yellon DM. Ischemic preconditioning protects by activating prosurvival kinases at reperfusion. Am J Physiol Heart Circ Physiol 2005; 288: H971-976.

42. Dobutovic B, Sudar E, Tepavcevic S, Djordjevic A, Radojcic M, Isenovic ER. Effects of ghrelin on protein expression of antioxidative enzymes and iNOS in the rat liver. Arch Med Sci 2014; 10: 806-816.

43. Yang S, Li H, Tang L, Ge G, Ma J, Qiao Z, Liu H, Fang W. Apelin-13 protects the heart against ischemia-reperfusion injury through the RISKGSK-3ß-mPTP pathway. Arch Med Sci 2015; Oct 1211 (5): 1065-1073.

Received February 12, 2018. Accepted March 5, 2018. 